\title{
INCREDIBLE DIVERSITY OF BEETLE WORLD INCLUDES 9,000 SPECIES IN CANADA
}

KEN PIVNICK, Box 306, Blaine Lake, SK SOJ 0J0

This article originally appeared in the Saskatoon Sun

Beetles are chewing insects with two pairs of wings: the front pair forms a hard leathery shield over the other pair, which it uses to fly. A fairly typical beetle is the lady bug or ladybird beetle, that ferocious predator of aphids. An early 20th-century entomologist once said, "God must have loved beetles; He made so many of them." About 340,000 beetle species have been described by scientists. This is about 40 per cent of the 850,000 living insect species so far described, and 24 per cent of the 1.4 million described species, including all living things. Terry Erwin of the Smithsonian Institution estimates beetle species numbers world-wide at up to 12 million, most of them in the tropics. There are an estimated 9,000 beetle species in Canada; perhaps 4,000 of them live in Saskatchewan.

Part of our lack of awareness stems from the names we give them. Some beetles are variously referred to as fireflies, June bugs, lady bugs, and weevils. Glow worms, wireworms, flat-headed borers, and whitegrubs are all beetle larvae (immature states which are somewhat worm-like and often referred to as "grubs").

Beetles are in many cases difficult to see. Many of them are soil-dwelling and very small. We do recognize the Cabbage Flea-beetle only because it tends to be numerous in our gardens or in canola fields. Other beetles are hidden away. The Poplar Borer, for instance, is a common and very beautiful metallic yellow-green beetle. The sign of activity of its immature stage, a white larva, is highly visible in April and May. It is noticed in Trembling Aspen when you see sap dripping from a small hole containing a small pile of wood fibres.

Bark beetles, two species which are making the news because they spread Dutch Elm Disease, are about two $\mathrm{mm}$ long and live, for the most part, under the bark of trees. Attractive orange and black Carrion Beetles are common and big but tend to congregate around dead animals. In fact, they will lay eggs on mouse-size carcasses, bury them and guard them against other beetles. We think of "lady bugs" as a single kind of insect, but there are at least 64 species of them in Saskatchewan.

Why are there so many kinds? Like other insects, beetle success in numbers of species can be attributed in part to their small size, making specialization on a small resource profitable. Beetles are also prolific and mobile, and separate stages specialize in surviving adverse conditions (eggs, pupae), eating (larvae) and reproduction (adults). In addition, they are particularly well armoured, and their generalized body design is very adaptable in evolutionary terms to new modes of living. 